\title{
Performance Investigation of Scheduling Algorithms for LTE Networks
}

Mohammad Masoom Zafar, Ammar Hafeez

Department of Electrical Engineering

COMSATS Institute of Information Technology, Lahore

mohammadmasoomzafar@gmail.com

ammarhafeez5@gmail.com

ABSTRACT: LTE is a mobile communication standard, which was introduced by $3 G P P$. LTE is fastest and latest technology with revolutionary data rate, high spectral efficiency, high user fairness, useful bandwidth, high throughput, less delay and low packet loss ratio etc. LTE support many applications. LTE in its services is facing many problems like improper scheduling, allocation of improper resources and unequal fairness to the user end devices. Goal of this paper is investigating downlink scheduling algorithms, to check the best one in multiple scenarios specifically for real time applications like video and VoIP in already existing algorithms. The best one algorithm will be more optimal with fairness, throughput, packet loss ratio, high spectral efficiency and proper allocation of resources to the user end devices. This paper also provides better understanding about fairness in detail.

Keywords: LTE (Long Term Evolution), 3GPP(3rd Generation Partnership Project), VoIP(Voice Over IP), QoS (Quality of Serves)

DOI: $10.6025 / \mathrm{jnt} / 2018 / 9 / 3 / 73-84$

Received: 17 May 2018, Revised 25 June 2018, Accepted 3 July 2018

(C) 2018 DLINE. All Rights Reserved

\section{Introduction}

\subsection{Fairness Index}

In wireless networking domain, generally, fairness is characteristic for beneficial aid distributing or assigning of resources. Where, unfair useful resource assign effect, amongst distinct human beings also can bring about beneficial aid starvation, useful resource loss or unnecessary resource allocation. However fairness in most cases, researched in resource Assigning [1]. Next question that comes in our mind obviously is when unfairness happens than which are the techniques we should perform?

Journal of Networking Technology Volume 9 Number 3 September 2018 
This isn't researched in detail. Typically, researchers centered on measuring the fairness in resource allocations. Devising strategies to mitigate unfairness is also a critical element of fairness. Unfairness occurs Once, then there are sorts of techniques that should be perform at the same time $[2,3]$ :

- Balancing entities which are dealt with unfairly in the prior resource assignment turn period. By using some way entities damages are focused within modern-day spherical for assignments.

- To attain the fairness again, regulate the assignment of resources, in favor of the people handled unfairly with no any settlement.

\subsection{Fairness Types}

If we focus on targeted fairness, it strives to get fair distribution of resources on the other hand resultant fairness proclaims for fair use.

Short- period fairness concentrates on just resource allocation for an awful short period of time. In other way, calculation of the fairness is happened at some specified instants. Quite the reverse, long-period fairness finds the assigning of resource designed for an extended duration of time (otherwise till end of time duration). But it is very hard to guarantee the short-period fairness with rare resources, when various individuals are striving for long-term measurements.

If we talk in sense of the system and individual, then Fairness is assumed on both stages. The system fairness focuses on the whole fairness surrounded by every user in the system. On the other hand, individual fairness specifies that either any individual user is acted equally by the system or not? [4]

\subsection{Utility}

Sign of utility might denote performance or efficiency in major circumstances and situations. For example, this is frequently merely classified as throughput, latency and additional performance factors. In this paper, the word "utility" denotes the metric that could point out either the resource assigning assure an entity or not? From performance index Utility was generally transformed, not including the fairness [5].

Following 3 terms utility, fairness and resource assigning are dissimilar to each other:

This is proved that; in resource allocation utility is a basic rule. Guarantee the reasonable fairness is an additional necessary rule for allocation. Thus, resource allocation is the achievement though fairness and utility. Limiting the allocation is done by these two rules (utility and fairness) [6].

\subsection{Fairness Index Measures: Jain's Fairness Index}

Expression for Fairness Index measure, is given below [1]

$$
\frac{\left(\sum_{i=1}^{n} x_{i}\right)^{2}}{n \sum_{i=1}^{n} x_{i}^{2}}
$$

Here $x_{i}$ is the stabilized (normalize) good put (or throughput; which is maximum number of useful bits per second in Kbps) for the $i$-th TCP (Transmission Control Protocol) scheme and $n$ is the number of links.

\subsection{Scheduling}

Main goal of a Scheduler is to get the optimize allocation of the resources in the units like time, frequency and power etc for the UEs, with satisfying level of QoS. "Scheduling means if you have number of resources and you have to decide that how to distribute them in different active users for their QoS requirements". Scheduler exists in the Base Station. It controls the assigning of RBs among Users with the defending of intra-cell interference. For different networks there are different schedulers $[11,12,13]$. List of schedulers is provided in figure 3. Packet scheduler's job is the use of different sources of information to allocate resources and coordinate activities, so that interference can be avoided. It also has the freedom of controlling the allocation of resources in time, frequency and power domains.

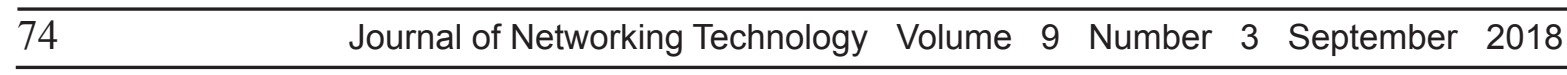




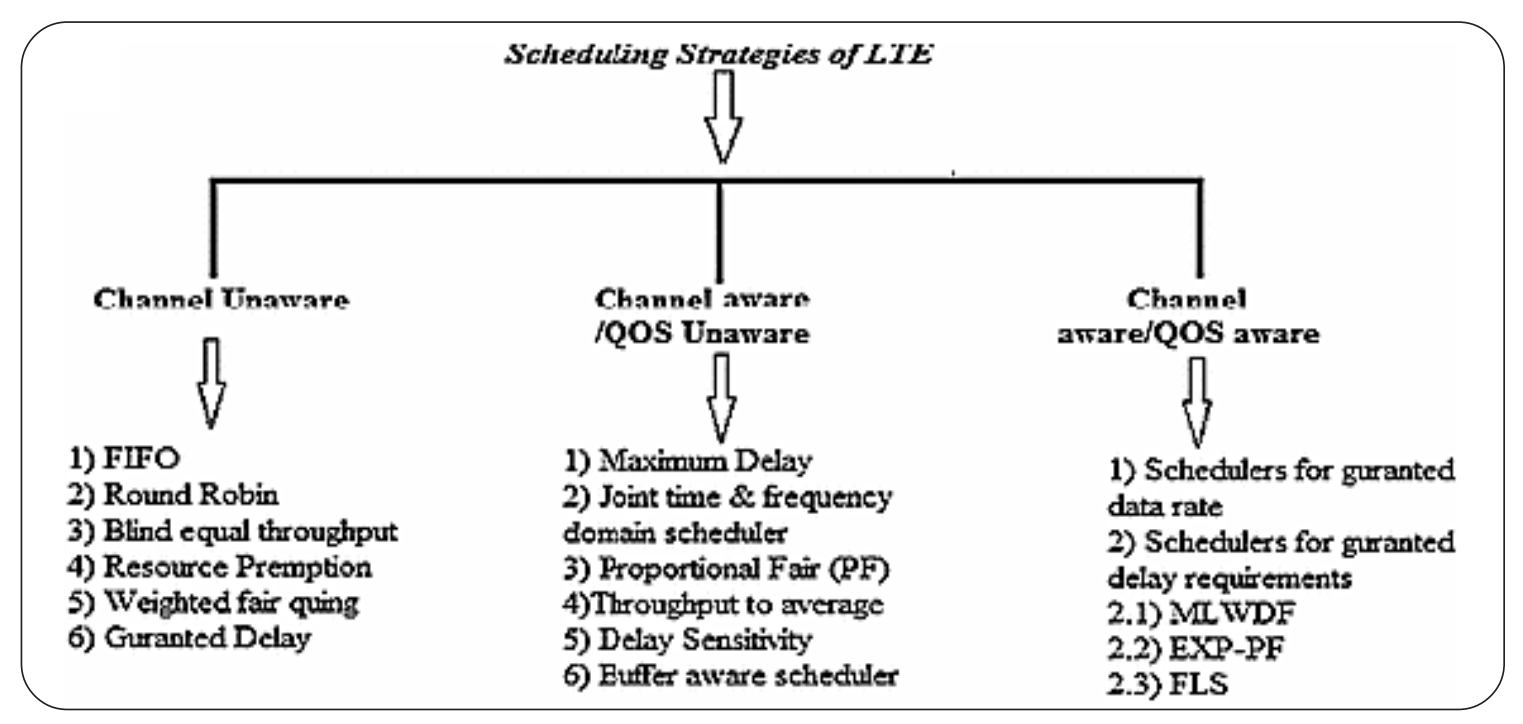

Figure 1. Scheduling Strategies of LTE

\section{Performance Investigation}

\begin{tabular}{|l|l|}
\hline Parameter & Value \\
\hline No. of Cells & 1 \\
\hline Radius of Cell & $1 \mathrm{KM}$ \\
\hline No. of Macro Users & $10-50$ \\
\hline Traffic & VOIP, VIDEO \\
\hline Schedulers Type & PF, MLWDF, EXPPF, FLS, OPTEXP, OPTLOG \\
\hline Frame Structure & Frequency Division Duplex (FDD) \\
\hline Speed & $3 \mathrm{KM} / \mathrm{hr}, 30 \mathrm{KM} / \mathrm{hr}$ \\
\hline Max Delay & $0.1 \mathrm{~ms}$ \\
\hline Video Bit Rate & $242 \mathrm{~kb} / \mathrm{s}$ \\
\hline Cell Transmit Power & $43 \mathrm{dBm}$ \\
\hline Bandwidth & $5 \mathrm{MHz}$ \\
\hline Homogeneity & Macro only \\
\hline Mobility Model & Random \\
\hline
\end{tabular}

Table 1. Simulation Parameters

\subsection{Methodology}

We have performed simulations on a simulator known as LTE-Simulator; which is an open source frame work. We run simulations for major six existing schedulers to check throughput, spectral efficiency, PLR and fairness. Here we checked the best scheduler for each environment.

\subsection{Results}

Graphs for $3 \mathrm{kmph}$ 


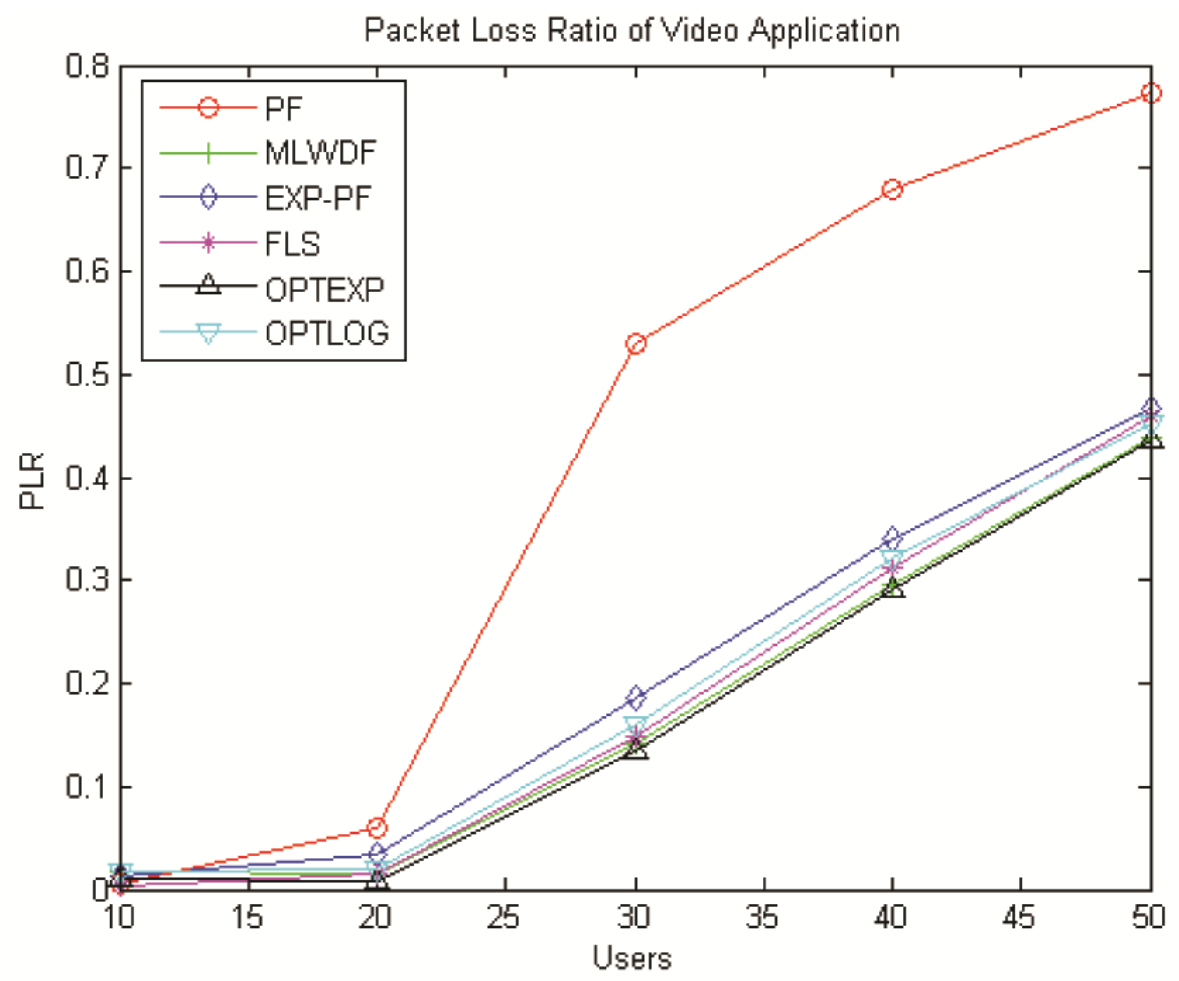

Here in this case; PF has maximum PLR. OPTEXP has highest performance, because it has least PLR. As the number of user increases PLR also increases.

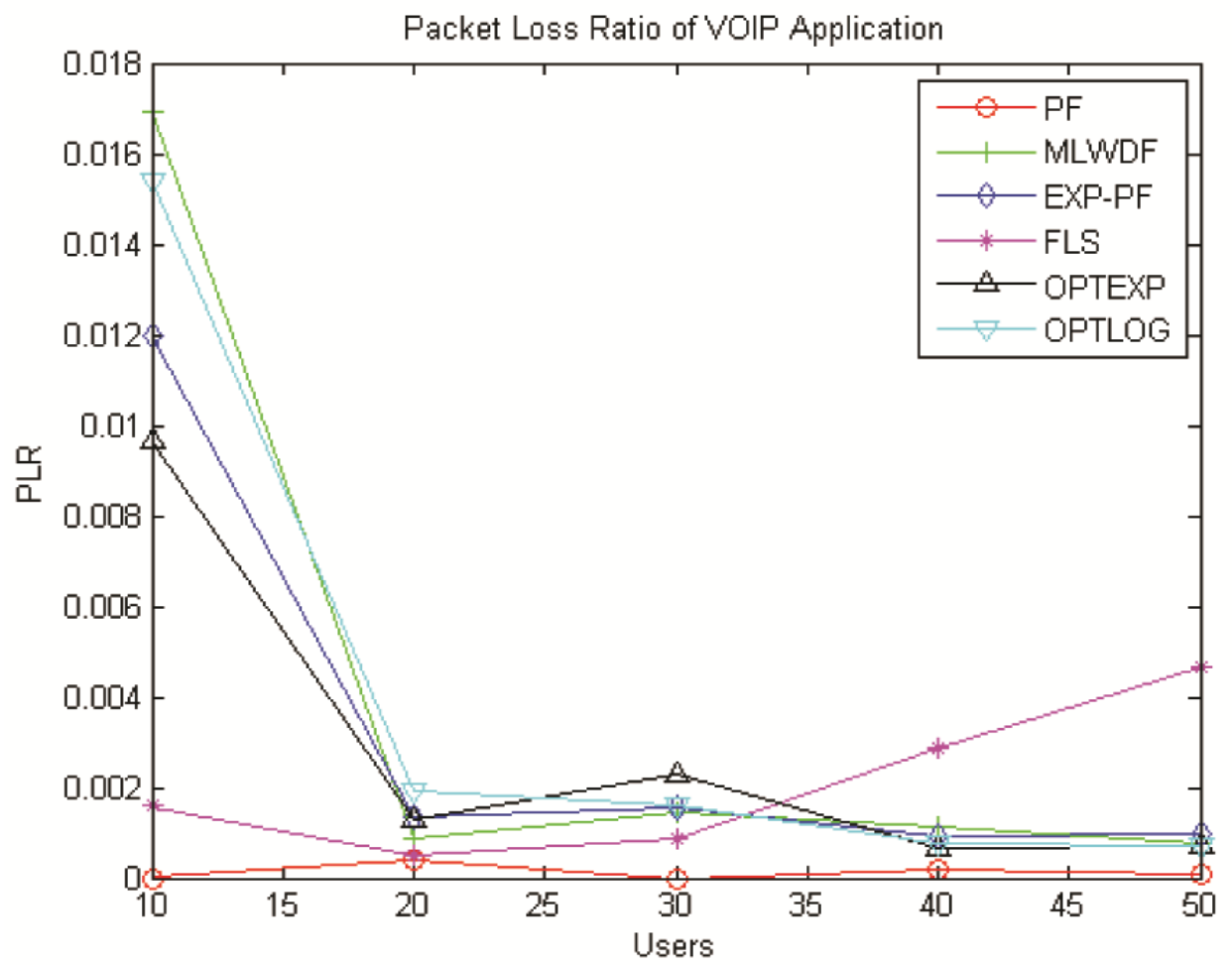

In this case; PF has minimum PLR. MLWDF has highest PLR average. As the number of user increases; PLR decreases. 


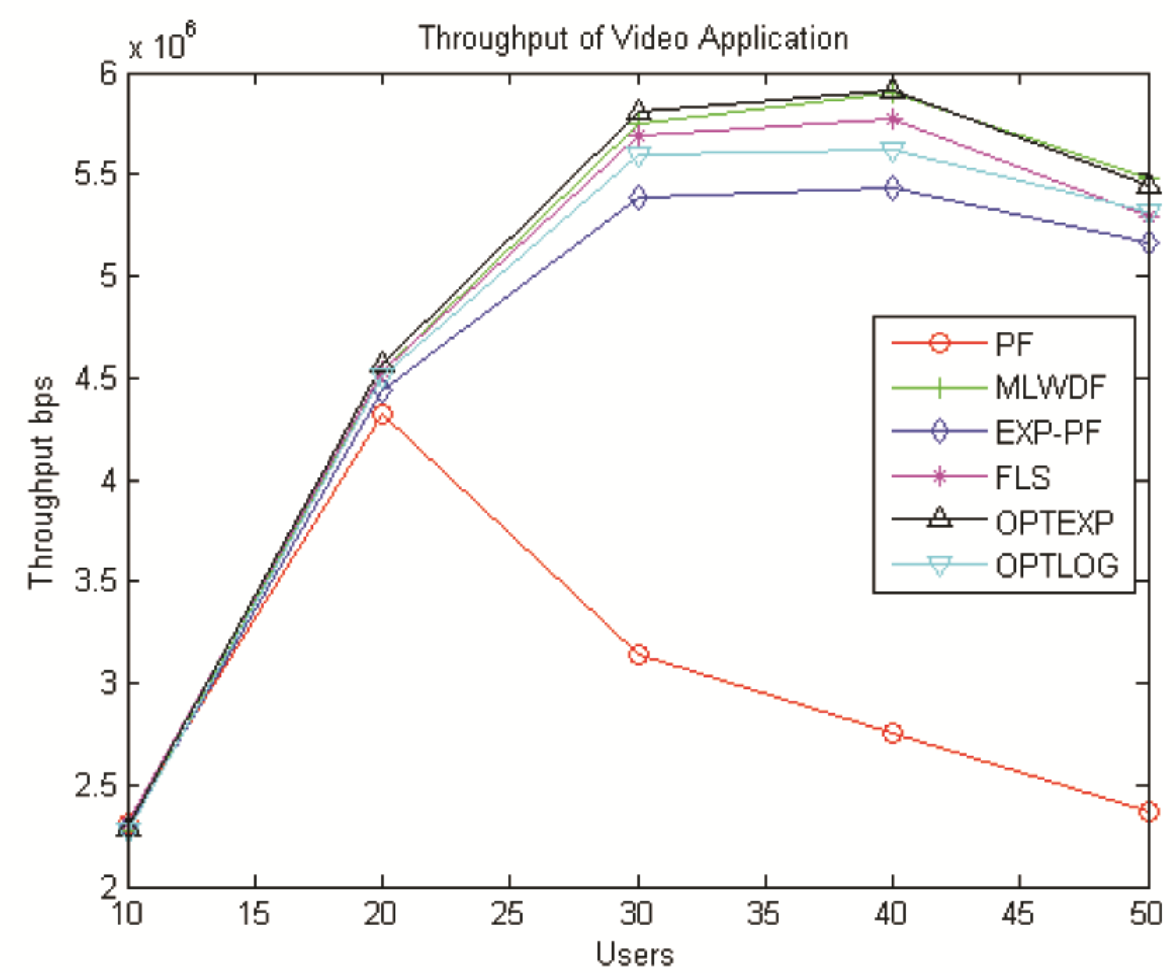

Here in this scenario; PF has minimum throughput. And throughput fluctuates as users increase. OPTEXP has highest throughput average.

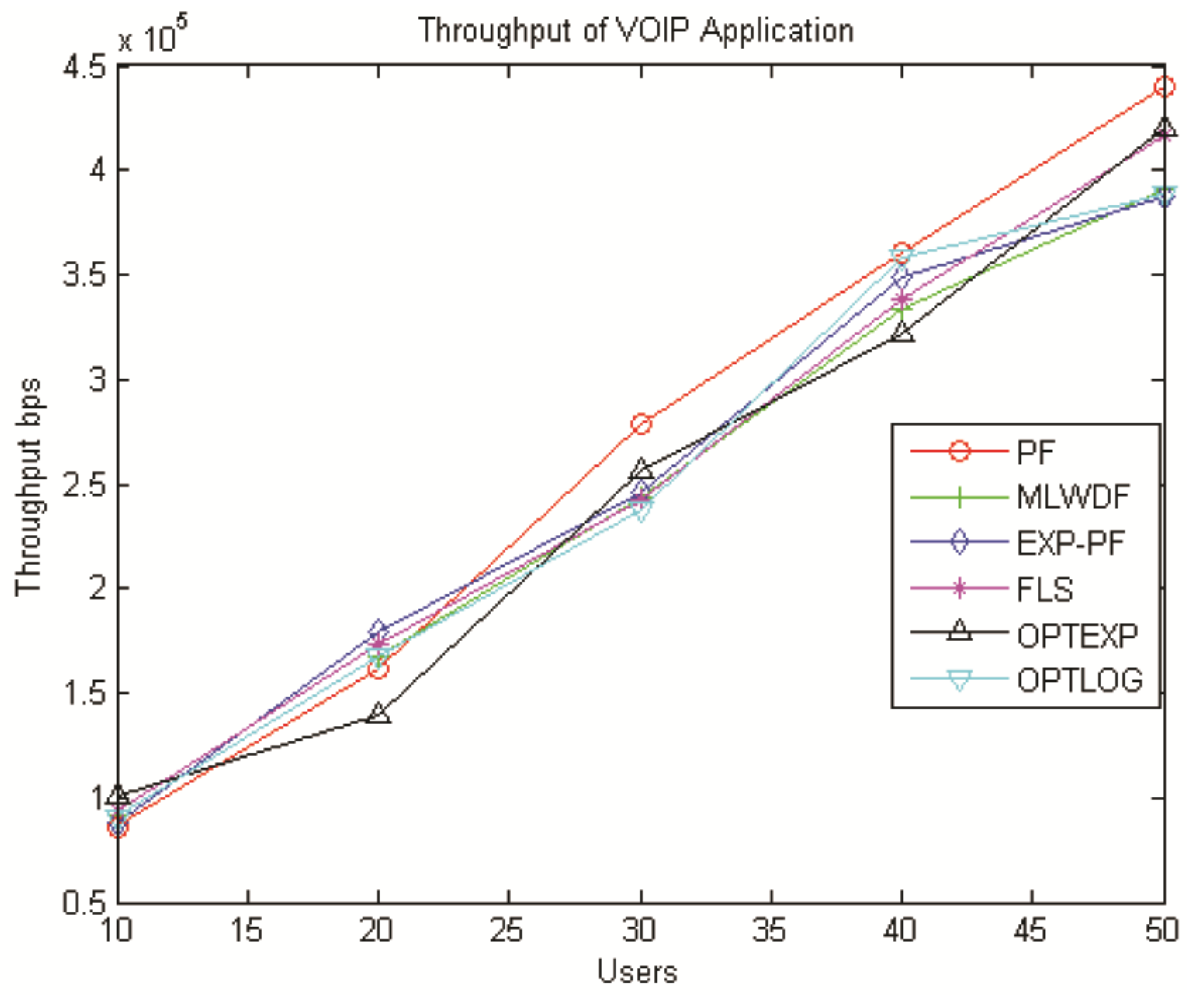

Here PF has maximum throughput. And throughput increases as users increase. MLWDF has highest throughput average.

\begin{tabular}{llllll}
\hline 78 & Journal of Networking Technology & Volume & 9 & Number 3 & September 2018 \\
\hline
\end{tabular}




\subsection{Graphs for $30 \mathrm{kmph}$}

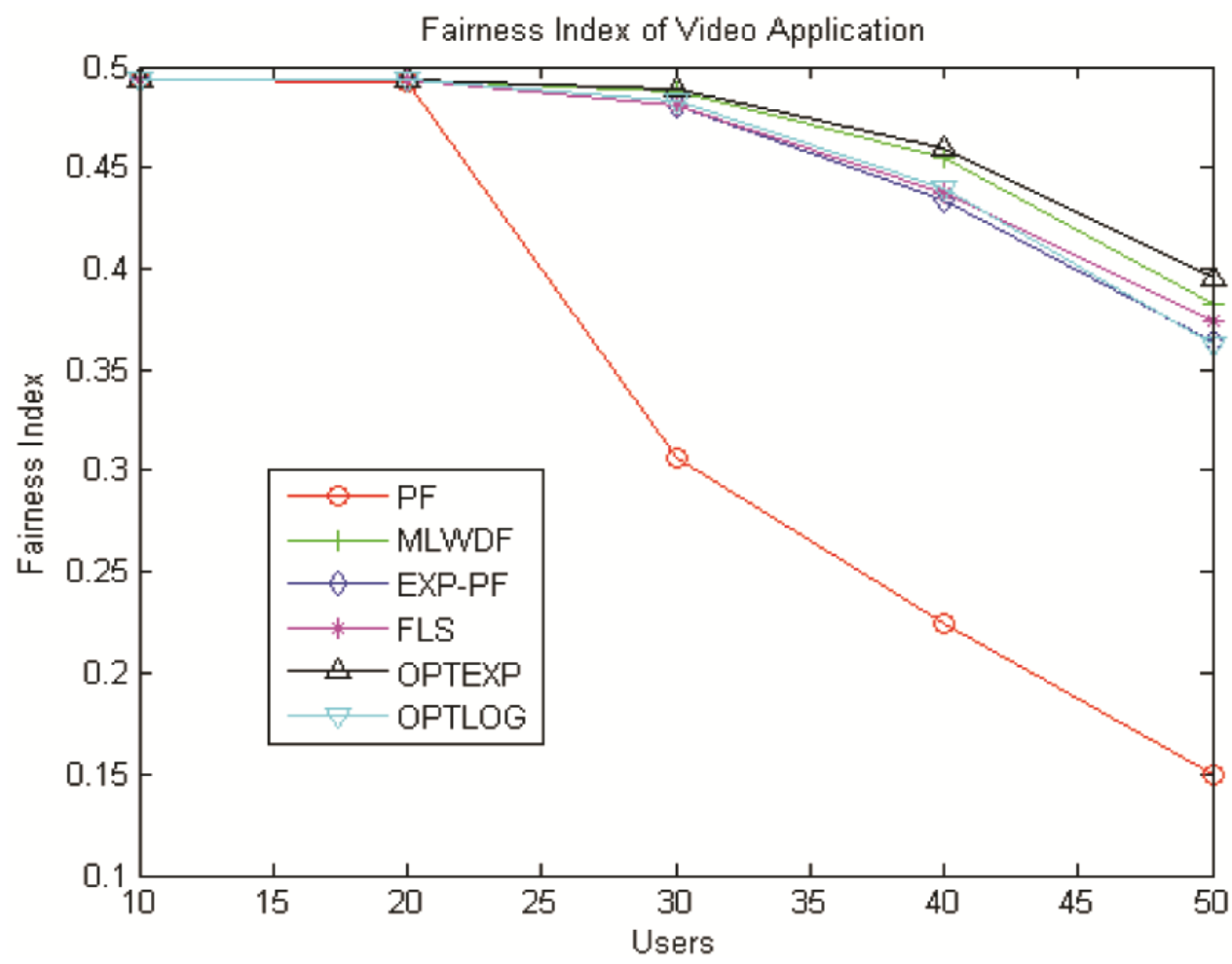

Here PF has least fairness and OPTEXP has highest fairness. As the number of user increases; fairness decreases for all schedulers.

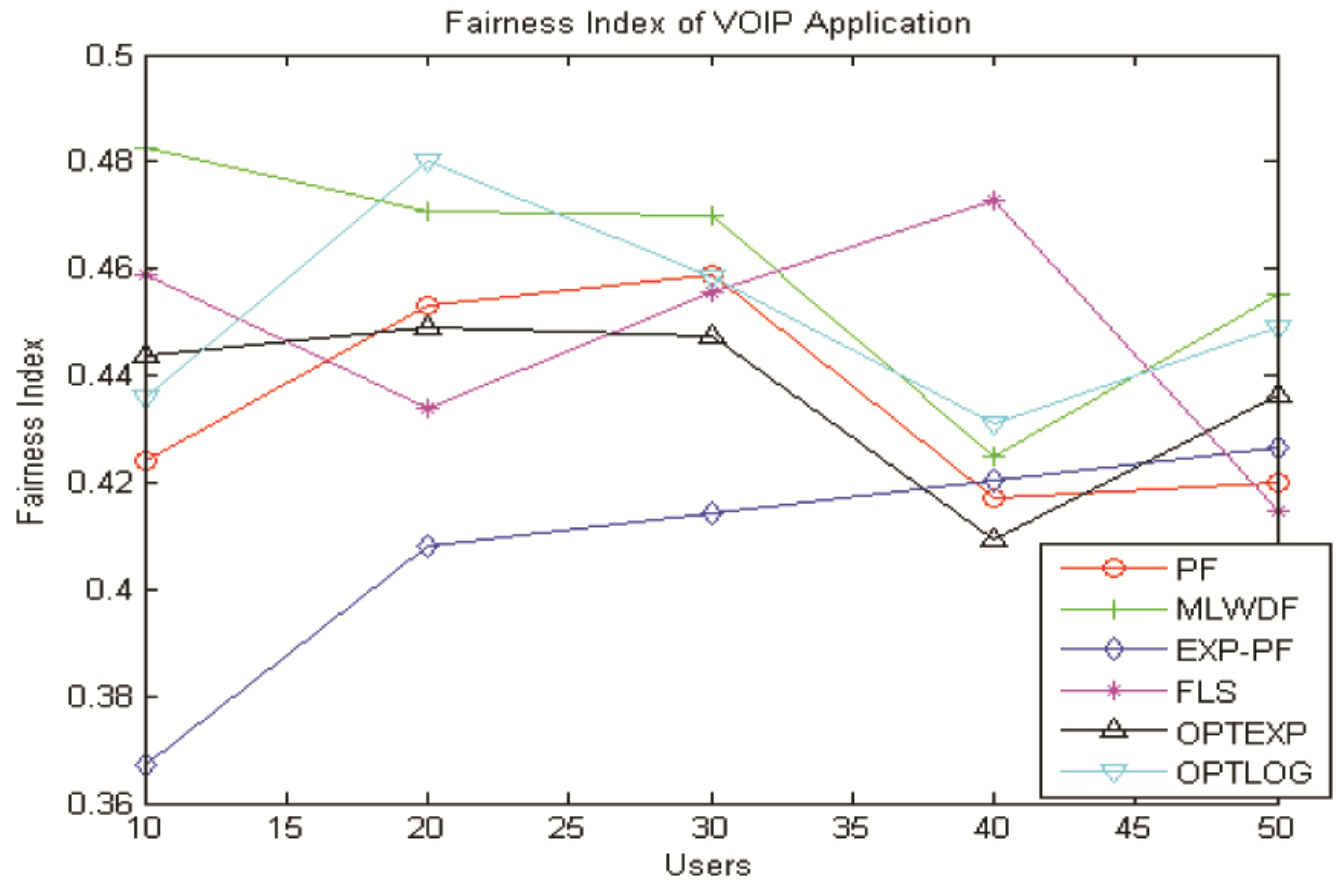

Here MLWDF has maximum fairness till 50 users. MLWDF has highest fairness average. As the number of users increases, fairness fluctuates for all schedulers. 


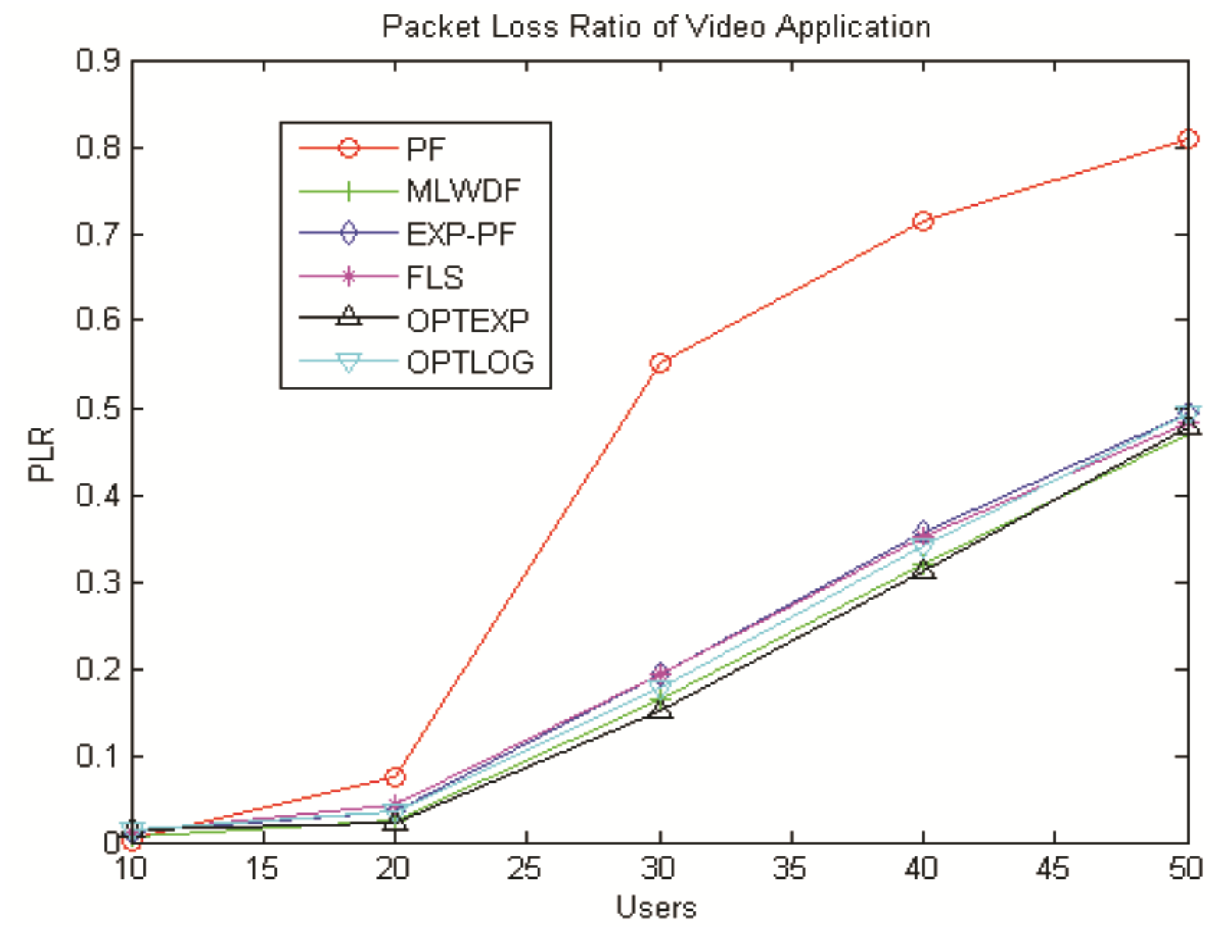

Here in this case; PF has maximum PLR. OPTEXP has highest performance, because it has least PLR. As the number of user increases PLR also increases.

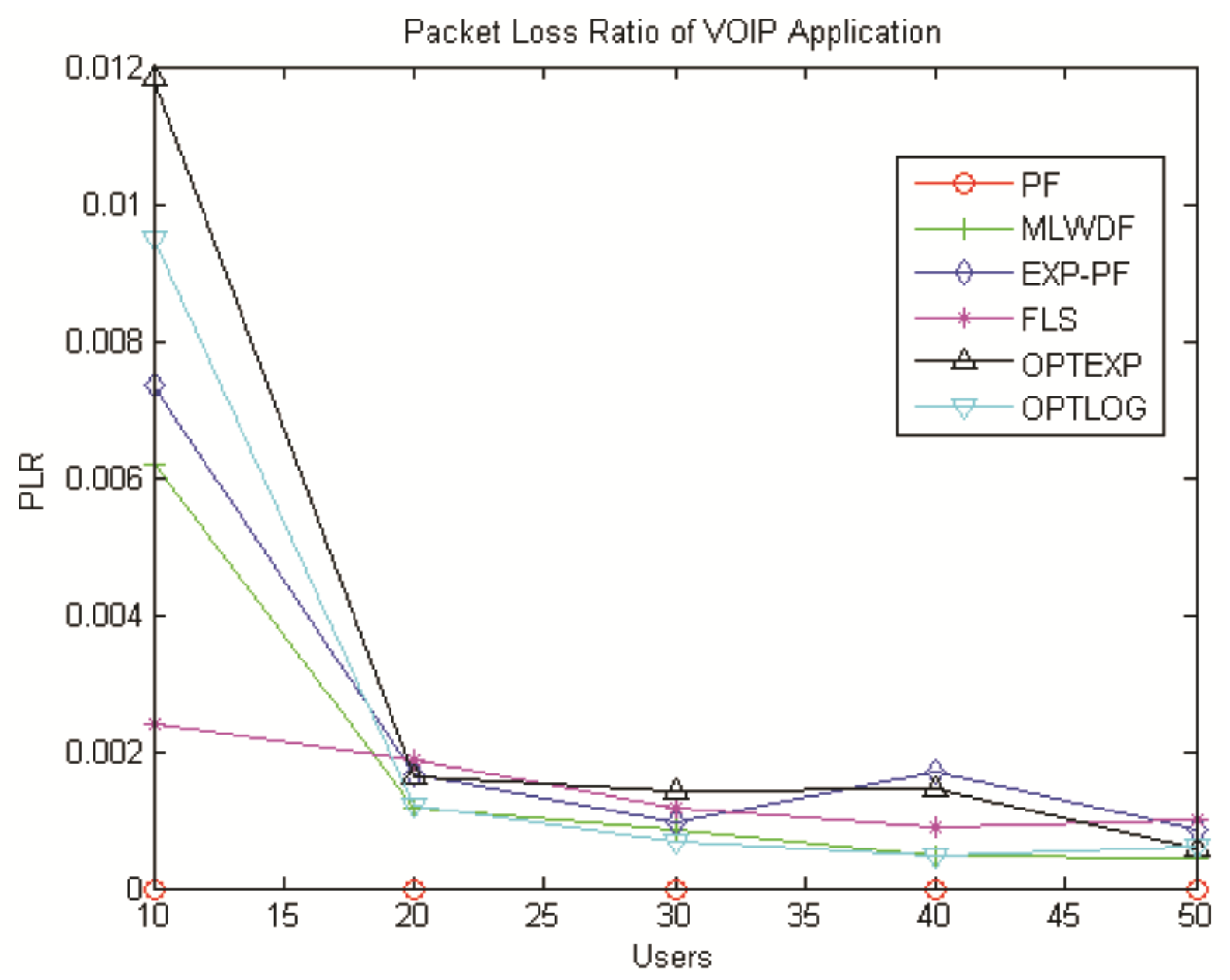

In this case; PF has minimum PLR. OPTEXP has highest PLR average, because it has maximum PLR. As the number of user increases; PLR decreases. 


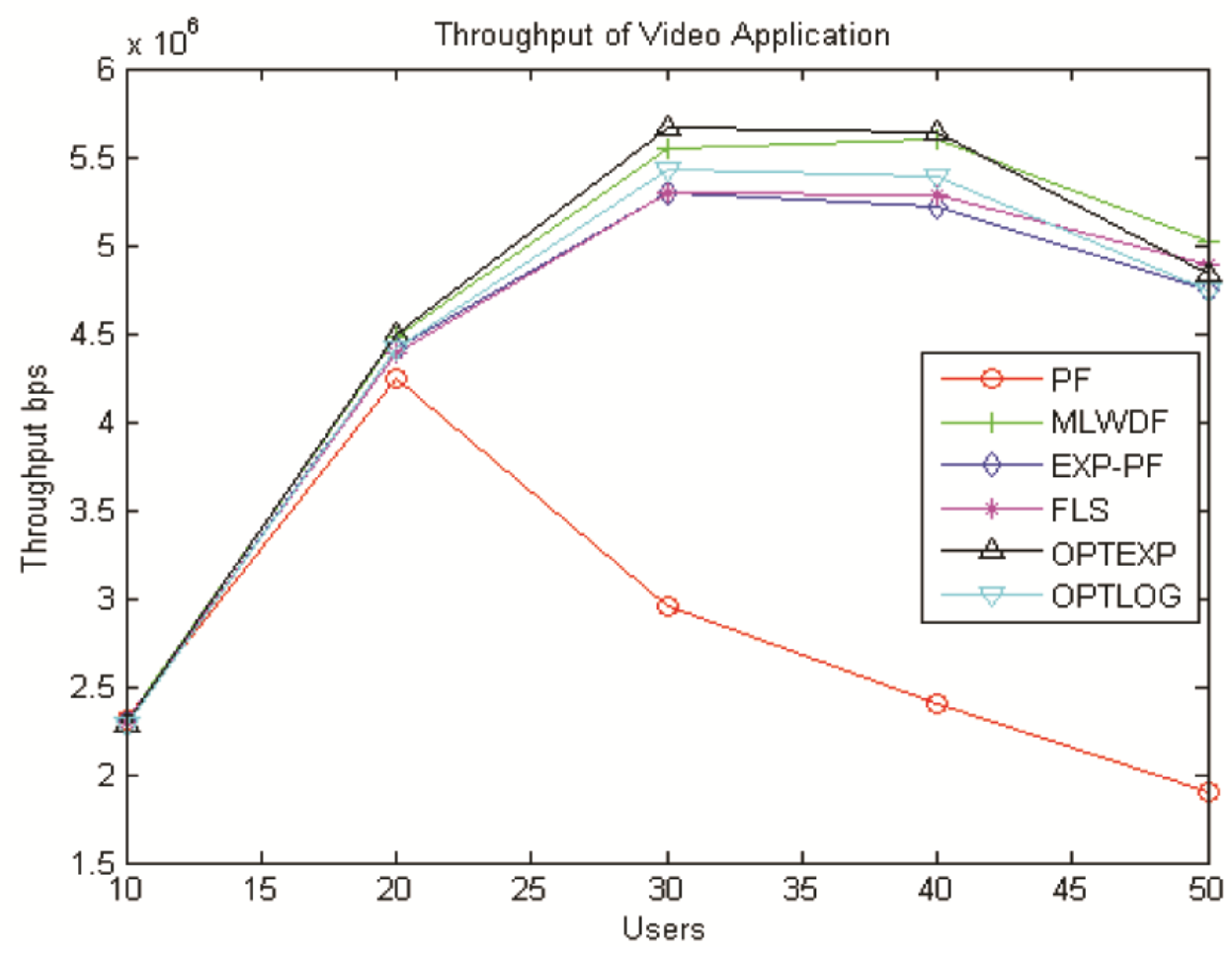

Here PF has minimum throughput of 10 users till 50 users. And throughput fluctuates as users increase. OPTEXP has highest throughput average.

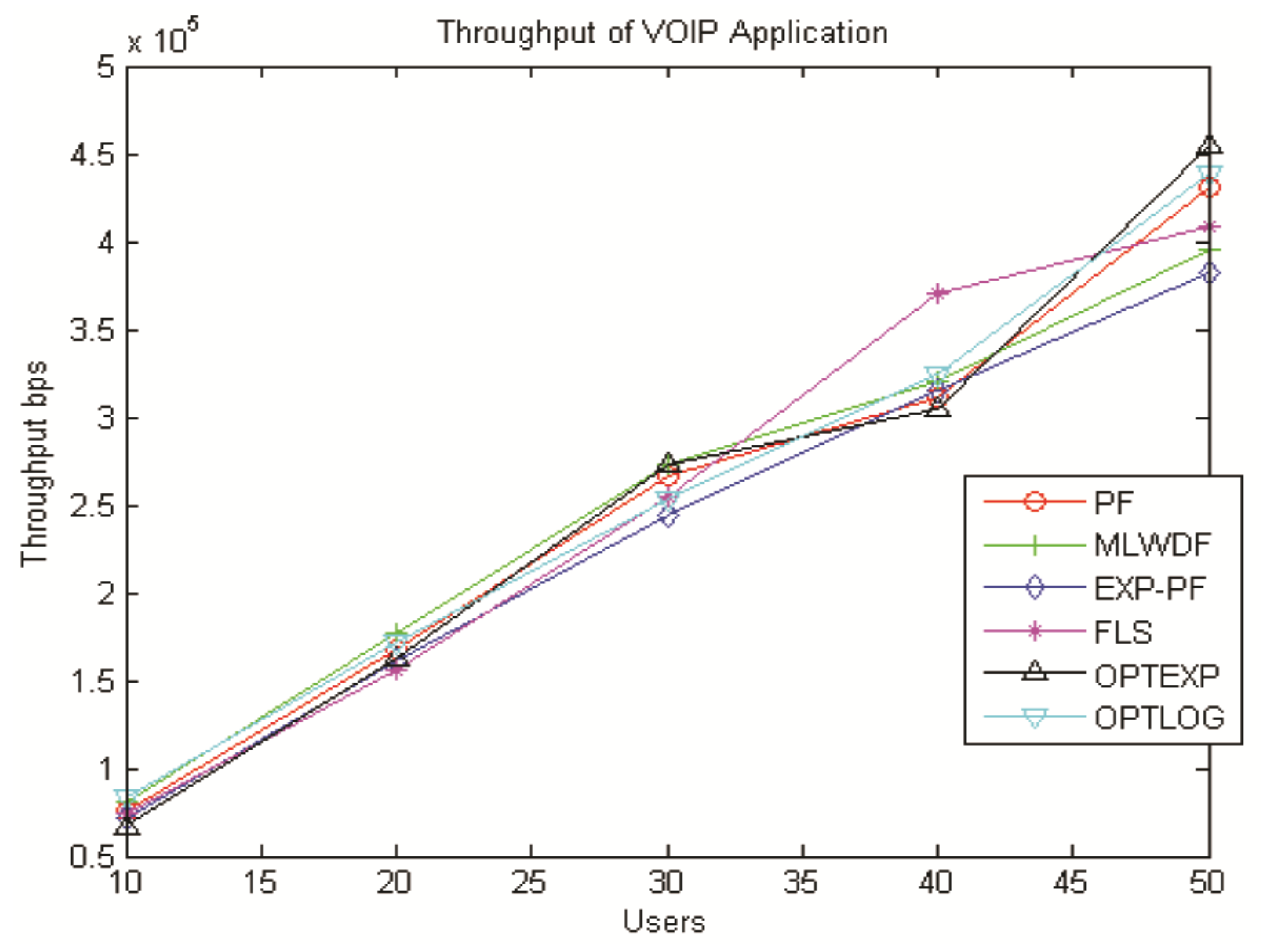

Here in this scenario; PF has maximum throughput from 10 users till 50 users. And throughput increases as users increase. OPTEXP has maximum throughput of $0.45 \mathrm{Mbps}$ for 50 users. 


\subsection{Summary of Results}

1. Fairness for Speed $3 \mathrm{KM} / \mathrm{hr}$

\begin{tabular}{|l|l|l|l|}
\hline \multicolumn{2}{|c|}{ Video Traffic } & \multicolumn{2}{c|}{ VoIP Traffic } \\
\hline PF & $7.7 \%$ & PF & $29.9 \%$ \\
\hline MLWDF & $13.7 \%$ & MLWDF & $30.2 \%$ \\
\hline EXPPF & $12.8 \%$ & EXPPF & $30 \%$ \\
\hline$\underline{\text { FLS }}$ & $\underline{\mathbf{2 4 . 2 \%}}$ & FLS & $29.2 \%$ \\
\hline OPTEXP & $19.6 \%$ & OPTEXP & $28.9 \%$ \\
\hline OPTLOG & $13.3 \%$ & $\underline{\text { OPTLOG }}$ & $\underline{\mathbf{3 1 . 5 \%}}$ \\
\hline
\end{tabular}

2. Throughput (bits/s) for Speed $3 \mathrm{KM} / \mathrm{hr}$

\begin{tabular}{|l|l|l|l|}
\hline \multicolumn{2}{|c|}{ Video Traffic } & \multicolumn{2}{c|}{ VoIP Traffic } \\
\hline PF & 645848.4 & PF & 422273.6 \\
\hline MLWDF & 2115186 & MLWDF & $\underline{\mathbf{4 4 5 1 2 4 . 8}}$ \\
\hline EXPPF & 1874926.8 & EXPPF & 420201.2 \\
\hline$\underline{\text { FLS }}$ & $\underline{\mathbf{5 2 4 6 9 7 0 . 8}}$ & FLS & 400695.4 \\
\hline OPTEXP & 3256251.2 & OPTEXP & 418514.4 \\
\hline OPTLOG & 2043779.6 & OPTLOG & 436600 \\
\hline
\end{tabular}

3. PLR for Speed 3KM/hr

\begin{tabular}{|l|l|l|c|}
\hline \multicolumn{2}{|c|}{ Video Traffic } & \multicolumn{2}{c|}{ VoIP Traffic } \\
\hline PF & 0.92 & PF & 0.0007 \\
\hline MLWDF & 0.737 & MLWDF & 0.005 \\
\hline EXPPF & 0.764 & EXPPF & 0.002 \\
\hline$\underline{\text { FLS }}$ & $\underline{\mathbf{0 . 4 6 8}}$ & $\underline{\text { FLS }}$ & $\underline{\mathbf{0 . 0 0 1}}$ \\
\hline OPTEXP & 0.623 & OPTEXP & 0.0009 \\
\hline OPTLOG & 0.745 & OPTLOG & 0.002 \\
\hline
\end{tabular}

4. Fairness for Speed 30KM/hr

\begin{tabular}{|l|l|l|l|}
\hline \multicolumn{2}{|c|}{ Video Traffic } & \multicolumn{2}{c|}{ VoIP Traffic } \\
\hline PF & $10 \%$ & PF & $28.5 \%$ \\
\hline MLWDF & $26.6 \%$ & MLWDF & $29.1 \%$ \\
\hline EXPPF & $25.9 \%$ & EXPPF & $30.30 \%$ \\
\hline$\underline{\text { FLS }}$ & $\underline{\mathbf{3 2 . 7 \%}}$ & FLS & $30.8 \%$ \\
\hline OPTEXP & $28.7 \%$ & $\underline{\text { OPTEXP }}$ & $\underline{\mathbf{3 1 . 4} \%}$ \\
\hline OPTLOG & $25.7 \%$ & OPTLOG & $30.34 \%$ \\
\hline
\end{tabular}


5. Throughput (bits/s) for Speed 30KM/hr

\begin{tabular}{|l|l|l|l|}
\hline \multicolumn{2}{|c|}{ Video Traffic } & \multicolumn{2}{c|}{ VoIP Traffic } \\
\hline PF & 887056 & PF & 427720 \\
\hline MLWDF & 2154261.2 & MLWDF & 438509.2 \\
\hline EXPPF & 2075976 & EXPPF & 407799.2 \\
\hline$\underline{\text { FLS }}$ & $\underline{\mathbf{5 1 3 9 6 6 7 . 8}}$ & $\underline{\text { FLS }}$ & $\underline{\mathbf{4 3 9 6 7 8 . 4}}$ \\
\hline OPTEXP & 3044184.8 & OPTEXP & 426092 \\
\hline OPTLOG & 2165614.4 & OPTLOG & 421104.4 \\
\hline
\end{tabular}

6. PLR for Speed $30 \mathrm{KM} / \mathrm{hr}$

\begin{tabular}{|l|l|l|l|}
\hline \multicolumn{2}{|c|}{ Video Traffic } & \multicolumn{2}{c|}{ VoIP Traffic } \\
\hline PF & 0.814 & PF & 0.0006 \\
\hline MLWDF & 0.689 & MLWDF & 0.001 \\
\hline EXPPF & 0.706 & EXPPF & 0.0018 \\
\hline FLS & $\underline{\mathbf{0 . 1 9}}$ & $\underline{\text { FLS }}$ & $\underline{\mathbf{0 . 0 0 0 8 1}}$ \\
\hline OPTEXP & 0.544 & OPTEXP & 0.0008 \\
\hline OPTLOG & 0.689 & OPTLOG & 0.00208 \\
\hline
\end{tabular}

Note: Best Results are underlined and bolded.

\section{Summary}

The 3GPP LTE goals intend to get highest data speed, spectral elasticity with faultless mobility and improved QoS above a whole IP system. In this project, we have performed some scheduling algorithms for LTE Advanced networks. By scheduling algorithms we distribute radio resources. Between UEs in well-organized method to improve the fairness of system. Finally we investigate the performance of different scheduling algorithms for macro environment. We also summarized the results for different environments.

\section{References}

[1] Acharya, J., Gao, L., Gaur, S. Heterogeneous networks in LTE-Advanced.

[2] Xiang, X., Lin, C., Chen, X., Shen, X. (2014). Toward Optimal Admission Control and Resource Allocation for LTE-A FC Uplink, IEEE Trans. Veh. Technol. 1-1.

[3] Fouziya Sulthana, S., Nakkeeran, R. (2014). Study of Downlink Scheduling Algorithms in LTE Networks, Journal of Networks, 9(12).

[4] Sahoo, B. (2013). Performance Comparison of Packet Scheduling Algorithms For Video Traffic In Lte Cellular Network, International journal of Mobile Network Communications \& Telematics, 3 (3) 9-18.

[5] Capozzi, F., Piro, G., Grieco, L., Boggia, G., Camarda, P. (2013). Downlink Packet Scheduling in LTE Cellular Networks: Key Design Issues and a Survey, IEEE Communications Surveys \& Tutorials, 15 (2) 678-700.

[6] Rathika, M., Sivakumar, P. (2016). A Survey on Resource Scheduling Algorithms of LTE 4G Wireless Communication, 2015. [Online]. Available: http://www.ijae.in/current_issue/paper5.pdf. [Accessed: 24- May-2016]. 
[7] AlQahtani, Salman, A., Alhassany, Mohammed. (2013). Comparing Different LTE Scheduling Schemes, 2013 IEEE.

[8] McQueen, D. (2009). The momentum behind LTE adoption, IEEE Commun. Mag., 47 (2) 44-45.

[9] Sauter, M. (2011). From GSM to LTE. Chichester, West Sussex, U.K. Wiley.

[10] Kanagasabai, A., Nayak, A. (2015). Channel Aware Scheduling Algorithm for LTE Uplink and Downlink, NPA, 7 (3) 111.

[11] Liu, S., Zhang, C., Zhou, Y., Zhang, Y. (2015). Delay-Based Weighted Proportional Fair Algorithm for LTE Downlink Packet Scheduling, Wireless Personal Communications, 82 (3) 1955-1965.

[12] Chadchan, S., Akki, C. (2013). A Fair Downlink Scheduling Algorithm for 3GPP LTE Networks, International Journal of Computer Network and Information Security, 5 (6) 34 - 41.

[13] Radhakrishnan, S., Neduncheliyan, S., Thyagharajan, K. (2016). A Review of Downlink Packet Scheduling Algorithms for Real Time Traffic in LTE-Advanced Networks, Indian Journal of Science and Technology, 9 (4).

[14] Lai, W., Tang, C. (2013). QoS-aware downlink packet scheduling for LTE networks, Computer Networks, 57 (7) 1689-1698.

[15] Robalo, D., Velez, F. (2015). Economic trade-off in the optimization of carrier aggregation with enhanced multi-band scheduling in LTE-Advanced scenarios, EURASIP Journal on Wireless Communications and Networking, 2015 (1).

[16] Ali, A., Nordin, R., Ismail, M., Abdullah, H. (2014). Impact of Feedback Channel Delay over Joint User Scheduling Scheme and Separated Random User Scheduling Scheme in LTE-A System with Carrier Aggregation, Journal of Computer Networks and Communications, vol. 2014, 1-7.

[17] Capozzi, F., Piro, G., Grieco, L., Boggia, G., Camarda, P. (2012). On accurate simulations of LTE FCs using an open source simulator, EURASIP Journal on Wireless Communications and Networking, 2012 (1) 328.

[18] Kumar, B., Prasad, D., Kumar, M. (2015). LTE-Advanced communication using in FCs Perspective, International Journal of Engineering and Computer Science.

[19] Piro, G., Grieco, L., Boggia, G., Capozzi, F., Camarda, P. Simulating LTE Cellular Systems: An Open-Source Framework, IEEE. 